\title{
Isolated left brachiocephalic trunk arising from the main pulmonary artery with right aortic arch
}

\author{
Girish Gowda S L, MCh, ${ }^{\text {a }}$. S. Seetharama Bhat, $\mathrm{MCh},{ }^{\mathrm{a}}$ M. Jayaranganath, DM, ${ }^{\mathrm{b}}$ and \\ Madhav Hegde, MD $^{\mathrm{c}}$
}

\begin{abstract}
Anomalous origin of the left brachiocephalic trunk from the main pulmonary artery with right aortic arch is an extremely rare congenital anomaly. These types of cases are incidentally diagnosed in adults and children with symptoms of vertebral basilar insufficiency. We report the clinical findings, investigation, and management of a case of this rare congenital anomaly.
\end{abstract}

\section{CASE REPORT}

A 5-year-old male child was referred to our institute for evaluation when a doctor performing a school health checkup noticed absent left radial pulsation. The patient and his parent reported a history of occasional weakness of left upper limb on physical exertion with no complaints of fainting or blurring of vision. Left upper limb and left carotid pulsations were absent. The upper limb arm circumferences were equal. The right upper limb blood pressure was $90 / 50 \mathrm{~mm} \mathrm{Hg}$, and the left upper limb blood pressure was $40 \mathrm{~mm} \mathrm{Hg}$ systolic (diastolic was not recordable). Oxygen saturations of the right and left upper limbs were $100 \%$

From the Department of Cardiothoracic and Vascular Surgery, ${ }^{a}$ the Department of Pediatric Cardiology, ${ }^{\mathrm{b}}$ and the Department of Radiology, ${ }^{\mathrm{c}}$ Sri Jayadeva Institute of Cardiovascular Sciences and Research, Bangalore, India.

Disclosures: Authors have nothing to disclose with regard to commercial support.

Received for publication March 18, 2013; revisions received June 27, 2013; accepted for publication July 3, 2013; available ahead of print Aug 26, 2013.

Address for reprints: Girish Gowda S L, MCh, Department of Cardiothoracic and Vascular Surgery, Sri Jayadava Institute of Cardiovascular Sciences and Research, Bangalore, Karnataka, pin-560069, India (E-mail: gowda1212@yahoo.co.in).

J Thorac Cardiovasc Surg 2014;147:822-3

$0022-5223 / \$ 36.00$

Copyright $($ c 2014 by The American Association for Thoracic Surgery

http://dx.doi.org/10.1016/j.jtcvs.2013.07.015 and $95 \%$, respectively. Pulse oximeter with plethysmography was weak on the left side. Transthoracic echocardiography showed right aortic arch and was not able to visualize origin of the left brachiocephalic trunk from the aortic arch. Pulmonary arterial pressure was normal. No intracardiac congenital anomalies were detected on echocardiography. Conventional angiography showed right aortic arch, and aortic arch angiography showed opacification of the left brachiocephalic trunk and main pulmonary artery via the circle of Willis. Selective injection into the left brachiocephalic trunk through the main pulmonary was done (Figure 1,A). Computed tomographic angiography showed an anomalous origin of the left brachiocephalic trunk from the main pulmonary artery at the level of bifurcation of the main pulmonary artery with right aortic arch (Figure 1, B). Intraoperatively, an anomalous left brachiocephalic trunk was seen arising from main pulmonary artery at its bifurcation point with a thin wall (Figure 1,C). The anomalous left brachiocephalic trunk was reimplanted into the aorta (Figure 2, A). Postoperatively, the patient had good left upper limb pulsation and good pulseoximeter with plethysmography. Postoperative computed tomographic angiography showed a normal branching pattern of right aortic arch (Figure 2, B). The patient is free of symptoms and doing well at 4 months of follow-up.

\section{DISCUSSION}

The Edwards hypothetic double aortic arch explains aortic arch abnormalities by selective regression of various parts of either arch. ${ }^{1}$ This abnormality can be explained by interruption at two sites in the double aortic arch, in the left
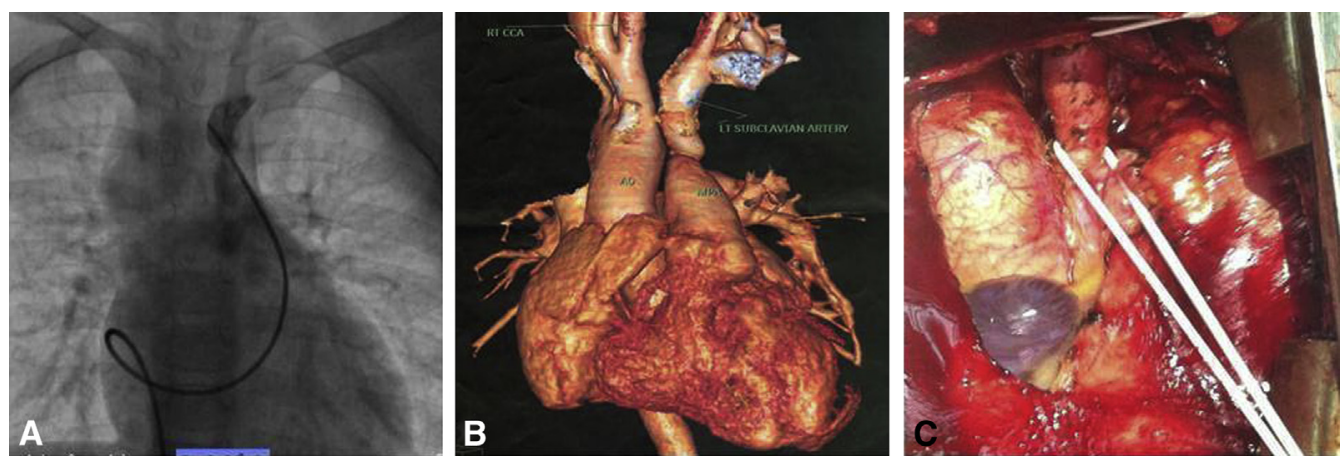

FIGURE 1. A, Cardiac catheterization showing the origin of the left brachiocephalic trunk from the main pulmonary artery. B, Cardiac computed tomography showing the origin of the left brachiocephalic trunk from the main pulmonary artery. C, Operative photograph showing the origin of the left brachiocephalic trunk from the main pulmonary artery. 

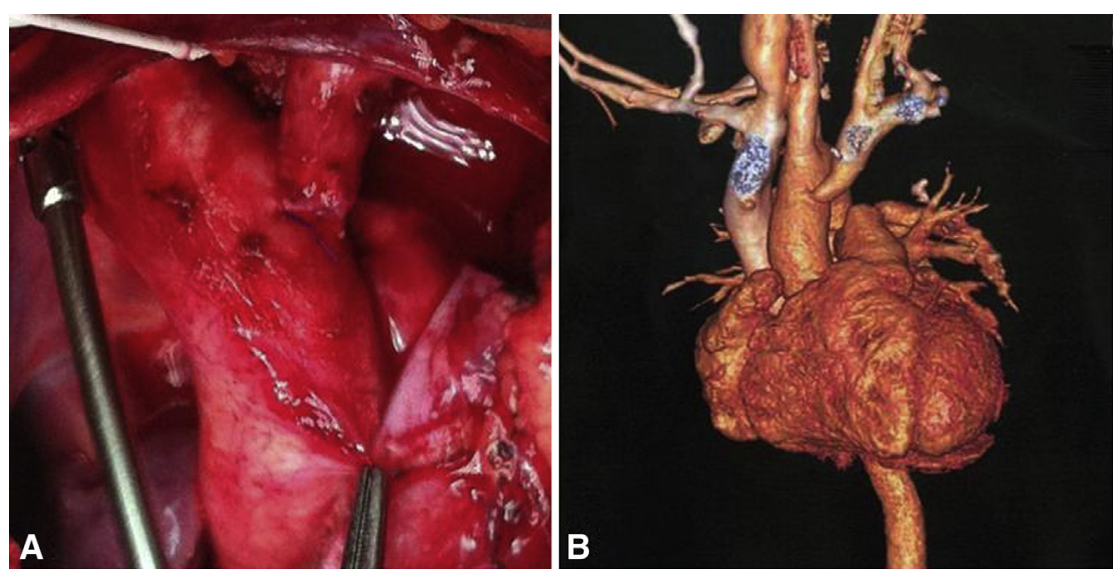

FIGURE 2. A, Operative photograph after translocation of the left brachiocephalic trunk to the aorta. B, Postoperative computed tomography showing the left brachiocephalic trunk translocated to the aorta.

posterior arch distal to the ductus and in the left anterior arch proximal to the left common carotid artery. ${ }^{1}$ An aortic arch vessel originating from the pulmonary artery is a very rare anomaly, and only a few cases with right aortic arch and left common carotid or subclavian artery arising from the pulmonary artery have been reported. ${ }^{2-4}$ Gil-Jaurena and colleagues $^{5}$ reported a similar case, but with an associated atrial septal defect. The case reported here did not include any other associated cardiac malformation, which according to the literature is an extremely rare malformation. These patients are usually free of symptoms or demonstrate vertebral basilar insufficiency. Our patient had weakness of the left upper limb on playing and had no symptoms of vertebral basilar insufficiency. Multiple imaging modalities were used to arrive at a diagnosis because of unusual clin- ical presentation. These malformations can be corrected surgically with satisfactory results.

\section{References}

1. Stewart JR, Kincaid OW, Edwards JE. An atlas of vascular rings and related malformations of the aortic arch system. Springfield (IL): Charles C Thomas; 1964: 3-13. 80-129.

2. Fong LV, Venables AW. Isolation of the left common carotid or left innominate artery. Br Heart J. 1987;57:552-4.

3. Huang SF, Wu MH. Left common carotid artery arising from the pulmonary artery in a patient with DiGeorge syndrome. Heart. 1996;76:82-3.

4. Kaushik N, Saba Z, Rosenfeld H, Patel HT, Martin K, Reinhartz O, et al. An isolated left common carotid artery from the main pulmonary artery: possible malseptation of the truncoaortic sac. Pediatr Cardiol. 2005;26:707-9.

5. Gil-Jaurena JM, Ferreiros M, Zabala I, Cuenca V. Right aortic arch with isolation of the left innominate artery arising from the pulmonary artery and atrial septal defect. Ann Thorac Surg. 2011;91:303. 